\title{
DISPOSITIVO DA EXPERIMENTACC̃̃O E PRODUCCÃO DO SUJEITO HOMO EXPERIMENTALIS EM UM CURRÍCULO DE CIÊNCIAS
}

\author{
Lívia de Rezende Cardoso* \\ Universidade Federal de Sergipe (UFS) \\ Marlucy Alves Paraíso** \\ Universidade Federal de Minas Gerais (UFMG)
}

RESUMO: Em noticiários, cinemas, desenhos, sites de relacionamentos, editais de financiamento, podemos encontrar a experimentação científica sendo discursivamente construída. Neste artigo, ela é analisada como um dispositivo que, em dado momento histórico, respondeu à urgência de se definir o que conta como ciência moderna ou não; o que é possível de ser comprovado teórico-experimentalmente. Além disso, esse dispositivo produziu um sujeito específico da ciência, que ganha certos contornos nas aulas de ciências. Argumentamos, aqui, que no discurso do ensino por experimentação acionase um conjunto de práticas e de técnicas para fazer aprender diferente e, assim, produzir o Homo experimentalis. Para tanto, foi realizada uma pesquisa de campo em aulas de ciências de uma escola pública de Belo Horizonte durante um ano. Usando ferramentas conceituais foucaultianas, pudemos encontrar demandas ao sujeito desse dispositivo: aquele que duvida, que precisa observar, registrar, testar, teorizar, desqualificar e criticar para alcançar uma autoridade por meio do método científico.

Palavras-chave: Ciências. Experimentação. Dispositivo.

http://dx.doi.org/10.1590/0102-4698121155

"Doutora em Educação pela Universidade Federal de Minas Gerais, professora do Programa de PósGraduação em Educação da Universidade Federal de Sergipe e Líder do Grupo de Estudos e Pesquisas em Educação Científica (GEPEC). E-mail: livinha.bio@gmail.com.

" Doutora em Educação pela Universidade Federal do Rio de Janeiro, professora do Programa de PósGraduação em Educação: Conhecimento e Inclusão Social da Universidade Federal de Minas Gerais e Líder do Grupo de Estudos em Currículos e Culturas (GECC). E-mail: marlucyparaiso@gmail.com. 


\title{
EXPERIMENTATION DISPOSITIVE AND HOMOEXPERIMENTALIS SUBJECT'SPRODUCTION IN SCIENCE'S CURRICULUM
}

\begin{abstract}
In TV news, movies, cartoons, social networking websites and funding notices we can find scientific experimentation being discursively constructed. In this paper, the scientific experimentation is analyzed as a device that, at a given historical moment, responded to the urgent need of defining what counts as modern science or not. This analysis can be proved theoretically and experimentally. Moreover, the dispositive produced a specific science that gets certain contours in science classes. We argue here that, in the discourse of teaching by experimentation, a set of practices and techniques is triggered to make learning in a different way possible and, thus, produces Homo experimentalis. Therefore, we conducted a field research during a year in science classes in a public school in Belo Horizonte City. Using Foucault's conceptual tools, we observed demands to the subject of this device, a subject that doubts and needs to observe, record, test, theorize, criticize and discredit to achieve an authority through scientific method.
\end{abstract}

Keywords: Science. Experimentation. Dispositive.

\section{INTRODUĈ̣̃O}

A experimentação pode ser encontrada em diferentes materiais e espaços muito além dos laboratórios científicos. Ela está em fôlderes, propagandas, sites, revistas, jornais, telas, escolas. Ela é divulgada e intimamente conhecida como "experimentação científica". Sua existência curricular é demasiadamente delimitada e sua presença é sempre requisitada para produzir necessidades, situações e sentidos. Afinal, por estar presente no imaginário do que é ser cientista - ao ser relacionada às grandes descobertas, às substâncias coloridas, aos reagentes explosivos, à dissecção de animais, à sofisticada aparelhagem laboratorial -, a experimentação vem, ao longo dos tempos, sendo entendida como o momento em que se faz ciência, em que se institui um saber importante sobre determinada coisa, objeto ou seres.

Em revistas, a experimentação é apresentada como aquilo que aprimora técnicas de cuidado com os corpos, que torna o tratamento de doenças mais eficaz, que distingue ciência de crenças. É, sobretudo, matéria de capa ${ }^{1}$. Entre reportagens de jornais, as experimentações científicas são publicadas e relacionadas ao desenvolvimento do país, à saúde, à educação, à economia, à política, ao agronegócio, à cultura, ao esporte $^{2}$. Idas ao cinema, por sua vez, colocam as pessoas em contato com o tecnológico e colorido mundo experimental de cientistas em laboratório. Produções cinematográficas, milionárias em alguns casos, embalam-nas com shows pirotécnicos de cor, luz e efeitos especiais 
nos telões, fascinando-as com filmes de ficção científica ${ }^{3}$. Para as crianças, a Discovery Kids disponibiliza os desenhos Show da Luna e Sid, o cientista, por meio dos quais crianças podem "pensar, falar e trabalhar como cientistas, embasando sua curiosidade natural pelo mundo"4.

Em comunidades do Orkut ${ }^{5}$, profissionais trocam experiências entre si, disponibilizam apostilas de práticas, defendem perspectivas investigativas, discutem a aplicabilidade de metodologias e roteiros de experimentos, sugerem inúmeros sites para simulação de experimentações em Ciências. Adolescentes, por sua vez, possuem comunidades $^{6}$ nas quais expressam veementemente suas opiniões sobre aulas experimentais ou, ainda, postam, via site YouTube, vídeos ${ }^{7}$ nos quais são protagonistas da experimentação ou filmam professores / as realizando-as. O Facebook comporta perfis com os quais se podem agrupar pessoas interessadas em aulas experimentais, em discutir suas aplicações em aula ou em fazer parte de experimentações científicas ${ }^{8}$.

Podemos reconhecer, no entanto, que a escola é o espaço privilegiado no qual a experimentação atua mais fortemente. As aulas experimentais são utilizadas como marketing para escolas quando fotos de laboratório em uso costumam "fazer parte dos panfletos de divulgação das grandes escolas, como se isso garantisse, per se, um ensino de melhor qualidade" (GIOPPO; SCHEFFER; NEVES, 1998, p. 45). Essa proposição de excelência por meio do ensino experimental também perpassa escolas públicas quando da aquisição de kits de laboratório escolar pelo setor público?. Além disso, livros didáticos são bem avaliados pelo Guia do Plano Nacional do Livro Didático quando apresentam atividades experimentais que reforçam o ensino por investigação (BRASIL, 2010); estudantes são premiados/as por utilizar sucata na produção de materiais de práticas em projeto de popularização do ensino ${ }^{10}$; professores/as são financeiramente incentivados/as pelo Ministério da Educação a realizar Feiras de Ciências de modo a estimular atividades de iniciação científica ${ }^{11}$; o governo busca parcerias internacionais na tentativa de melhorar as aulas de ciências no país e de incentivar alunos/as a seguirem carreira de cientistas ${ }^{12}$.

Com tudo isso, é possível entender a força da experimentação científica na contemporaneidade. Não nos referimos, apenas, às aulas experimentais - que são aqui compreendidas como todo trabalho prático em que o/a aluno/a participa e que envolve "manipulação e controle de variáveis" (VALADARES, 2006, p. 2). Referimo-nos, também, às outras versões da experimentação divulgadas em noticiários, telas de cinema, desenhos educativos, sites de relacionamentos e em projetos de incentivo e financiamento para seus usos. Se hoje a experimentação é amplamente divulgada, 
isso se deve ao seu papel de disponibilizar verdades científicas sobre o mundo e formar sujeitos afinados a esse modo de compreendêlo. Se a experimentação torna-se um dispositivo ao emergir em dado momento histórico e solicitar um sujeito de determinado tipo, ela busca sua consolidação ao circular em diferentes artefatos culturais.

Neste artigo, analisamos a experimentação como dispositivo em funcionamento em um currículo de ciências. Argumentamos que no discurso do ensino por experimentação aciona-se um conjunto de práticas e de técnicas para fazer aprender diferente e, assim, produzir um sujeito investigativo, o Homo experimentalis. Tal sujeito não é exclusivamente produzido no espaço escolar. Ele é produto de um investimento mais amplo que ganhou notoriedade na modernidade e tem se intensificado com o surgimento de múltiplos artefatos culturais. A escola, no entanto, tem ganhado destaque porque é, por excelência, uma maquinaria que engendra subjetividades modernas.

Para desenvolver tal argumento, foi realizada uma pesquisa de campo em aulas experimentais de Ciências de uma escola pública de Belo Horizonte-MG com duração de um ano letivo. A partir de etnografia pós-moderna (CARDOSO, 2012; JORDÃO, 2004; CLIFFORD, 1986) e da composição de um diário de campo ${ }^{13}$, deixamos experimentos, livros didáticos, roteiros, gestos, objetos, vestimentas, professores/as, alunos/as tornarem-se um currículo. Fundamentadas em teorias póscríticas da educação e do currículo, entendemos currículo como um artefato que diz como sujeitos "podem ser, como devem proceder e o que devem tornar-se" (PARAÍSO, 2006, p. 97); como territórios culturais "sujeitos à disputa e à interpretação, nos quais os diferentes grupos tentam estabelecer sua hegemonia" (SILVA, 2003, p. 135). Atentas às disputas culturais estabelecidas nos currículos, buscamos pelas especialidades demandadas e como tais demandas produzem efeitos a depender dos discursos que passam a atuar no currículo.

Ao nos embasarmos nessas perspectivas e definições, utilizamos na pesquisa que subsidia este artigo a análise do discurso foucaultiana e trabalhamos, sobretudo, com os conceitos "posições de sujeito" e "governo". Ao fazermos a análise do discurso, procuramos mostrar neste estudo como os diferentes discursos "remetem uns aos outros, se organizam em uma figura única, entram em convergência com instituições e práticas, e carregam significação que podem ser comuns a toda uma época" (FOUCAULT, 2005, p. 134). Ao atravessarem professores/as e alunos/as no currículo investigado, discursos convidam sujeitos a posicionarem-se por meio de "práticas pelas quais os indivíduos foram levados a prestar atenção a eles próprios" (FOUCAULT, 2006, p. 11). Isso correspondeu a investigar os modos de 
subjetivação, aqui compreendidos como "todos os processos e as práticas heterogêneas por meio dos quais os seres humanos vêm a se relacionar consigo mesmos e com os outros como sujeitos de um certo tipo" (PARAÍSO, 2006, p. 101). De modo complementar, buscamos neste estudo mostrar como se estabelece no currículo investigado o governo de alunos/as e professoras, já que o governo "implica em certos modos de educação e de transformação dos indivíduos, na medida em que se trata não somente, evidentemente, de adquirir certas aptidões, mas também de adquirir certas atitudes" (FOUCAULT, 1982, p. 02). Para tal, processam-se técnicas do eu e de dominação, que em seu conjunto constituem as tecnologias de subjetivação (PARAÍSO, 2007).

Para desenvolver a argumentação formulada, dividimos este artigo em mais três partes. Na primeira, explicitamos, brevemente, como a experimentação emergiu em dado momento histórico e funcionou como um dispositivo. Em seguida, discutimos como um conjunto de práticas é divulgado para produzir, em aulas experimentais, verdades científicas sobre o mundo e, assim, compor o sujeito que aprende diferente, age diferente, o sujeito investigativo. Por fim, mostramos a posição de sujeito Homo experimentalis que é minuciosamente produzida no currículo investigado e que circula amplamente em tantos outros espaços.

\section{DISPOSITIVO DA EXPERIMENTAÇÃO NO CURRÍCULO INVESTIGADO}

Um dispositivo pode ser definido como a rede de relações "estabelecidas entre elementos heterogêneos: discursos, instituições, arquitetura, regramentos, leis, medidas administrativas, enunciados científicos, proposições filosóficas, morais, filantrópicas, o dito e o não dito" (FOUCAULT, 2007b, p. 244). Um dispositivo combina "campos de saber, relações de poder e modos de subjetivação" (MARCELLO, 2009, p. 227). Um dispositivo "ensina os indivíduos a tornarem-se sujeitos dotados" (MAKNAMARA, 2011, p. 68) de uma característica específica. Ele "dispõe algo em uma organização peculiar, dentro de uma racionalidade particular” (MAKNAMARA, 2011, p. 69). Além disso, um dispositivo, "em um determinado momento, teve como função principal responder a uma urgência” (FOUCAULT, 2007b, p. 244).

Desse modo, a experimentação é aqui entendida como dispositivo que responde à urgência de se definir o que conta como ciência moderna ou não, o que é possível ou não de ser comprovado teórico-experimentalmente, o que garante ou não a "invenção dos meios para criar testemunho fidedigno" (STENGERS, 2000, p. 152). É o dispositivo da experimentação que revela, produz e institui as verdades 
e os saberes no discurso científico moderno, havendo, aí, um jogo duplo: "relações de força sustentando tipos de saber que dele nascem, mas que igualmente o condicionam" (FOUCAULT, 2007b, p. 246). Isto é, ao passo que tipos de saber são produzidos, o funcionamento do dispositivo da experimentação é condicionado às suas regras discursivas.

A experimentação, por conseguinte, é tida aqui como um dispositivo que aciona tecnologias de subjetivação, demandando o sujeito específico da experimentação em diferentes instâncias, instituições e espaços. O dispositivo da experimentação é um operador que, ao mesmo tempo, concerne às coisas e aos homens (LATOUR; WOOLGAR, 1997). Afinal, a ciência confere, a quem se diz cientista, a quem atende aos seus critérios de demarcação, "direitos e deveres" (STENGERS, 2000, p. 32). Ao passo que a experimentação surge como um dispositivo e ganha destaque na atualidade com a "função estratégica dominante" (FOUCAULT, 2007a), o sujeito da experimentação é solicitado. Um operador da experimentação, em suas práticas de laboratório, buscará atender aos seus deveres - racionalidade, objetividade, empiria, ordenação, lógica - e saberá usufruir dos seus direitos de autoridade.

O funcionamento do dispositivo da experimentação no interior da ciência moderna foi amplamente estudado por Isabelle Stengers, não sendo, portanto, objetivo deste artigo explorar a constituição histórica e a função da experimentação na ciência moderna. Interessa-nos tomá-la, apenas, como ponto de partida na ciência contemporânea para, assim, sinalizar uma crítica ao papel destacado que ela recebe nessa mesma ciência e nos programas de ensino. Nessa visão da experimentação como um dispositivo, de acordo com Stengers (2000, p. 152), a experimentação em laboratório científico é "capaz de calar os rivais, de instituir uma situação de comprovação cuja meta é o poder de representar". Vale ressaltar que essa autora esteve muito mais atenta a como esse dispositivo serve como "máquina de verdades" para a ciência. Aqui, entendemos que o dispositivo da experimentação atua em diferentes espaços, arranja arquiteturas, organiza instrumentos, produz cruzamentos discursivos, estabelece uma racionalidade, conecta um espaço específico a outras práticas culturais, demarca o que conta para ser verdade, define autoridades, estabelece métodos e metodologias, produz o padrão, institui normas, destina condutas, produz sujeitos Homo experimentalis.

Se a necessidade de se afastar de práticas não-científicas e medievais conferiu à ciência moderna a emergência de um método - o dispositivo em questão - , foi pela necessidade de se produzir um novo sujeito moderno que se acionaram diversas maneiras e 
meios de construí-lo socialmente. Se é no domínio do método, dos procedimentos experimentais, na conduta correta do cientista que se possibilita discutir se um conhecimento é ou não válido, autorizado e aplicável, passa-se, então, a investir em meios de produzir os sujeitos de tais procedimentos. Se a experimentação torna-se um investimento escolar, é porque o dispositivo da experimentação busca sua consolidação em diferentes espaços. Ensinar o modo de fazer ciência, seus métodos e seus efeitos é uma demanda produzida no currículo investigado e que passamos a analisar.

\section{ENSINO POR EXPERIMENTAC̣ÃO E SUAS ESTRATÉGIAS}

Explicitar o método, dizer de sua credibilidade e importância são práticas demandadas no currículo investigado pelo discurso do ensino por experimentação. Por meio desse discurso, é possível inserir as aulas experimentais no currículo de ciências; promover a simulação e o exercício do trabalho do cientista em laboratório; produzir sujeitos da experimentação. Uma de suas estratégias seria exaltar no currículo experimental a importância da experimentação para o progresso da ciência. Nele, divulga-se que, em 1870, Weissman "cortou a cauda de um casal de ratos e depois os cruzou, e observou que todos os filhotes nasceram com cauda. Cortou novamente a cauda dos filhotes e os cruzou. Fez isso durante 22 gerações. Em todas elas os filhotes nasceram com cauda de tamanho normal", o que contrariou as ideias de Lamarck até então aceitas (APEC, 2006, p.90). Em outro experimento, diz-se que as condições da "Terra primitiva foram reproduzidas em laboratório pelos norteamericanos Stanley Miller e Harold Urey", em 1953, e, a partir desse experimento, formularam-se as atuais hipóteses sobre a origem da vida (APEC, 2006, p. 104). Nessas enunciações, a experimentação é apresentada como marco, como o que muda a forma de pensar sobre certo tema e arranja novos ditos na ciência.

Essa autoridade alcançada por meio do dispositivo da experimentação é cara aos discursos científico e do ensino por experimentação. Ter, na escola, um currículo de ciências - que exalta o método experimental e ensina seus procedimentos - é tido aqui como um diferencial. Em diversas vezes, pudemos perceber o quanto a experimentação é usada como recurso didático nesse currículo, como aquilo que envolve e seduz os/as alunos/as para alcançarem um aprendizado dos conceitos científicos. Afinal, de acordo com o discurso do ensino por experimentação, no currículo de ciências, "existe uma diferença entre contar e ver cada experimento. É diferente falar 'a temperatura 
permanece constante' e ver isso. É preciso experimentar" (DC, p. 1). Além disso, "a aula experimental usa outros sentidos que não é só ouvir o professor ou olhar para o quadro" (DC, p. 1). O experimento tem o papel "de construir conhecimento com eles, de prepará-los para a vida" (DC, p. 11), o/a professor/a de "construir", "mediar o conhecimento" (DC, p. 24) e a escola de estar "com o olhar para o aluno" (DC, p. 25).

Enuncia-se, ainda, que, se a experimentação está presente no currículo, tem-se um diferencial porque "[os alunos] aprendem a pensar racionalmente. [Os alunos] têm as aulas de laboratório, sabem reconhecer um tubo de ensaio, uma grade, manuseiam o termômetro" (DC, p. 9). A professora Ângela, em seu momento de formação, por exemplo, via que tudo aquilo que o professor falava na teoria, ela conseguia ver na prática: "não era que eu aprendia mais quando eu fazia, é que eu aprendia de uma maneira que me facilitava. Eu percebi que era muito claro que quando eu fazia um experimento eu podia discutir um resultado com a teoria dos livros. Eu posso muito bem falar 'durante o processo de ebulição a temperatura permanece constante'. Eu fiz e vi que era verdade” (DC, p. 27). No discurso do ensino por experimentação, clama-se pela necessidade de construir o conhecimento na prática, de não apenas ouvir, mas de ver, de manusear, de fazer. Nesse currículo, ao se operar com um conjunto de verdades testáveis por meio da experimentação, seus sujeitos realizam operações em si e desejam tal forma disponibilizada de produzir. Certamente, como analisa Foucault sobre o governo de condutas, "quanto mais o governo governa pela verdade, no fundo ele irá governar tanto menos" (FOUCAULT, 2010, p. 45). Ou seja, quanto mais verdades são produzidas na experimentação, mais os sujeitos que a operam são conduzidos a se portarem como sujeitos desse discurso.

No discurso do ensino por experimentação, diz-se que "não é que os alunos estejam aprendendo mais, mas que os alunos estão aprendendo de uma maneira diferente". Acredita-se que essa maneira diferente de aprender propicia que "eles se apropriem do conhecimento e não fica só porque alguém conta. Na prática do permanganato, eles visualizam as partículas se movimentando mesmo o copo [que abriga a mistura] estando parado, veem que eu não mexi em nada. Eles visualizam a teoria naqueles procedimentos práticos" (DC, p. 28). Aprender por experimentação torna-se uma estratégia desse currículo para "presenciar a verdade", "ver com os próprios olhos", "construir o correto", "registrar evidências", "fazer ciência". A experimentação, método científico que garante racionalidade, objetividade e neutralidade àquele/a que a opera, é acionada no currículo de Ciências não apenas para ser sedutora e atrativa aos/ 
às alunos/as. A experimentação é imensamente utilizada porque, quando se trata de ciência, "o 'é verdade, portanto, eu me inclino' torna-se muito mais enigmático, muito mais obscuro" (FOUCAULT, 2010, p. 72). Em se tratando do governo, especificamente, de condutas científicas, a condução dos comportamentos torna-se mais eficaz porque há um conjunto de verdades que só serão descobertas caso seus sujeitos cumpram os procedimentos "corretos".

Afinal, não basta dizer, contar ou fazer, imaginar. Por meio da experimentação, é possível "provar" que o conhecimento científico é verdadeiro, que um fenômeno relatado na teoria, de fato, acontece na natureza, que a ciência consegue explicar qualquer mistério. Nessa prova, ensina-se a fazer da ciência e a produzir o sujeito do experimento, o sujeito investigativo: aquele que duvida de tudo, que precisa observar, revelar, registrar, testar, teorizar, desqualificar e criticar para alcançar uma autoridade por meio do método científico. Um sujeito produzido pelo discurso do ensino por experimentação, por um ensino pensado de modo a se opor ao ensino tradicional, livresco e demasiadamente teórico.

Para produzi-lo, procedimentos da experimentação são divulgados e ensinados no currículo experimental por meio de práticas de revelação, registro, teste e teorização. A prática de revelação, por um lado, diz respeito à operação de instrumentos para fazer aparecer, dar maior visibilidade, ampliar os detalhes que compõem um material na natureza. Um exemplo disso se dá quando há a advertência de que "precisamos pôr corante nas coisas para poder enxergá-las" (DC, p. 4). A prática de registro, por outro lado, consiste em observar e registrar características, condições ambientais, situações controle em um experimento. Encontramos recomendações de tal prática em diferentes situações de aula: "é importantíssimo anotar se é o lavado ou não, a data que começou e quando vamos tirar" (DC, p. 5); "não esquecem de anotar o que foi que vocês coletaram" (DC, p. 6); "a aluna que manuseou o tomate lavado no pote estava fora do controle, não tiveram cuidado com o registro" (DC, p. 18).

Quando práticas de registro são consolidadas, constrói-se, a partir delas, roteiros e protocolos a serem seguidos em laboratório ou no local de coleta e pesquisa. Desse modo, solicita-se atenção a instruções do passo a passo e registros em formulários que indicam as condições de coleta e experimentação: "aqui é um protocolo para chegarem em um ambiente qualquer e analisá-lo. Precisa chegar lá e observar tudo, colocar a data, como estava o tempo, se chovia ou tinha sol, se houve coleta ou não, como foi a forma de coleta, descrever o tipo de ambiente (rio, lago), se é calmo, profundidade, largura, temperatura da água. Como é a vegetação, se alguém mora perto, se há pastagem, 
indústrias, erosão" (DC, p. 35). Na aula sobre bioindicadores, em que se ensina como avaliar um ambiente a partir dos seres vivos presentes e de fatores físico-químicos, há demasiado investimento em definir quais parâmetros devem ser considerados. Recomenda-se que "para tudo ocorrer bem, vocês precisam fazer tudo que está no roteiro" (DC, p. 35). Quando se recorre a esses instrumentos, almeja-se "produzir comportamentos que só têm sentido em relação ao protocolo" (STENGERS, 1990, p. 108). Com esses instrumentos de inquérito - protocolos e roteiros -, "a verdade não tem mais como ser produzida. Ela terá de se representar e se apresentar cada vez que for procurada" (FOUCAULT, 2007a, p. 67) pelo sujeito investigativo.

Tais práticas discursivas propõem-se a revelar qualquer conhecimento sobre a natureza. Seguir roteiros e protocolos, observar, enxergar, fazer aparecer, anotar, descrever, estabelecer parâmetros são práticas que produzem o experimento. Por meio dele, "interrogamos fenômenos que tratamos em função de uma linguagem, de uma hipótese teórica. O problema não é estudar o fenômeno de maneira neutra, e sim de criar condições segundo as quais esse fenômeno dará testemunho" (STENGERS, 1990, p. 84). Isto é, em laboratório, "o operador define o tipo de testemunho procurado, o tipo de prática a que se deve recorrer para fazer daquilo a que nos dirigimos uma testemunha" (STENGERS, 1990, p. 92). É "esta forma singular de produção da verdade que pouco a pouco foi recobrindo as outras formas de produção da verdade e que, ou pelo menos, impôs sua forma como universal" (FOUCAULT, 2007a, p. 66). Se é desse modo que comportamentos científicos são produzidos em laboratórios como estudado por Stengers e Foucault, no currículo escolar aqui analisado, é por meio da investigação conduzida por registros, roteiros e protocolos que sujeitos são produzidos como investigadores, como experimentadores.

A possibilidade de definir o verdadeiro ao pôr algo à prova é possível quando se opera com a prática de teste. No roteiro da prática sobre "afunda ou flutua?", após tabela em que alunos/as anotam o que esperam do comportamento dos objetos na água, há o convite: "agora vamos testar a classificação de cada objeto, usando a vasilha de vidro contendo água". No livro didático, é apresentada uma pesquisa experimental que avaliou o efeito de antissépticos bucais, concluindo, após "inúmeros testes em laboratório", que cinco das seis marcas são eficientes (APEC, 2006, p. 129). Em outra aula, recolhe-se o material que deu discordância sobre a densidade para poder tirar a prova com um experimento (DC, p. 37). Ao se notar que eles/as não querem opinar, diz-se: "ai gente, não tenham medo. Eu também não sei. Eu não fiz o experimento antes” (DC, p. 45). Quando houve discordância 
nas opiniões, sentencia-se em uma aula: "é? Vamos ver na prática!" (DC, p. 52). Em meio a dúvidas, impasses e incertezas, o dispositivo da experimentação, tal qual acontece nos laboratórios científicos, aciona a prática do teste para trazer a certeza: "ela é verdadeira, foi verificada, tem autoridade" (STENGERS, 1990, p. 105).

Como é por meio da experimentação que se traz a verdade, demanda-se que o sujeito investigativo, quando está em dúvida ou suspeita, opere tal prática de teste para que a verdade logo surja. Desse modo, no currículo investigado, questiona-se: "vocês sabiam que quando estamos com sintoma de garganta inflamada, todo médico devia fazer uma cultura? Passar o cotonete na garganta, depois semear numa placa de petri e deixar desenvolver" (DC, p. 5). Adverte-se que: "se eu pego um copo de água [do rio] e nela não vem peixe, posso dizer que é de má qualidade? Não gente, só posso ter uma suspeita! Não posso afirmar nada. O que vou ter que fazer é pesquisar para saber o porquê de não ter peixe" (DC, p. 22). Aconselha-se, ainda, que: "se só encontro eles [caramujos], preciso fazer outros testes para saber se a água é boa ou não" (DC, p. 22). Ao referir-se a produtos industriais reciclados, esclarece-se que "são feitos testes, pois quem desenvolve está preocupado com o mercado" (DC, p. 41). A experimentação é aí requisitada como uma estratégia do discurso científico, pois "o que está em questão é o que rege os enunciados e a forma como estes se regem entre si para constituir um conjunto de proposições aceitáveis cientificamente e, consequentemente, susceptíveis de serem verificadas ou infirmadas por procedimentos científicos" (FOUCAULT, 2007a, p. 4).

Feita a execução de etapas e procedimentos, passa-se à organização e interpretação dos resultados, compondo a prática de teorização. Assim, primeiro, ensina-se: "você tem de construir de modo racional, acadêmico, científico" (DC, p. 12) os gráficos e as tabelas finais para poder "interpretar os dados obtidos" (DC, p. 8). Concomitante a essa etapa, é dito aos/às alunos/as que "é preciso saber o que quero dos meus dados" nessa construção. Depois, conduzem-se alunos/as a interpretar os resultados do experimento pelo que "o gráfico nos diz" (DC, p. 11). Na prática proposta sobre o efeito estufa em um dos livros, há a simulação desse fenômeno com materiais simples. Nas páginas seguintes, retoma-se muito dos resultados obtidos por meio dele para se teorizar sobre tal fenômeno (APEC, 2009, p. 161). Esse fazer científico padronizado - que organiza gráficos e tabelas e que deles solicita uma verdade, que olha os resultados segundo o que se deseja interpretar - insere-se em um regime de verdade: "aquilo que define, que determina a forma desses atos; é aquilo que 
estabelece para esses atos condições, efetuações e efeitos específicos" (FOUCAULT, 2010, p. 67). Por meio de tal regime, define-se como proceder frente aos dados para, em seguida, inferir, ordenar e teorizar.

No experimento para variar o brilho da lâmpada, várias situações são colocadas e, para cada uma delas, pede-se que os/as estudantes tirem conclusões sobre o que acontecerá (APEC, 2006, p. 173). Após a realização da prática "afunda ou flutua", questiona-se: "você seria capaz de formular uma regra geral que permitisse dizer que objetos flutuem?”. Na prática "todo plástico é igual?”, pede-se que: "após a análise do esquema e da realização do experimento ordene os quatro tipos de plásticos em ordem crescente". Ao convocar os alunos/as a refletirem sobre o que e com quais métodos se pesquisa, o currículo investigado opera com a ciência no sentido de esta ser "uma família de jogos de verdade que obedece todos ao mesmo regime no qual o poder da verdade foi organizado de maneira que a constituição seja assegurada pelo próprio verdadeiro" (FOUCAULT, 2010, p. 74). Assim, a verdade científica é vivenciada pelo sujeito investigativo por meio de suas produções internas acerca de seus métodos e procedimentos. A verdade científica é por ele produzida, portanto, quando se revela, registra, testa e teoriza sobre um fenômeno experimentado.

\section{AUTORIZAC̣̃̃O POR MEIO DA INVESTIGAC̣ÃO}

"Você não pode dizer mais dessa forma. Lembre-se que já provamos isso para você quando a professora Ângela trouxe o experimento com a lâmina" (DC, p.45). O status de verdade obtido pela experimentação é tido, nesse currículo, como inquestionável quando se percorre as práticas até aqui analisadas. Quando o sujeito investigativo assim procede, almeja-se alcançar o status de verdade por meio da ciência. Afinal, o conceito científico "nasce quando um operador está munido com a pretensão de ser legítimo em um campo determinado, de julgar um campo determinado" (STENGERS, 1990, p. 75). No currículo experimental, para tornar-se verdadeiro e autorizado, precisaria, ainda, operar com as práticas de autorização, desqualificaşão e crítica.

A prática de autorização pode ser observada em algumas situações. $\mathrm{Na}$ aula de análise ambiental, anuncia-se que, para ganhar prestígio e autoridade, necessita-se fazer experimentações: "se eu pesquiso para proteger um lago ou rio e eu chego lá e não vejo alguns animais, eu poderei chegar para um governante e uma população e dizer 'ei, nós precisamos preservar aquilo ali"' (DC, p.34). Além disso, garante-se que "a auto-sustentabilidade do país depende muito de pesquisador maluco 
que faz isso aí [experimentos]" (DC, p.42). Em outra aula, afirmase que: "células tronco são células que ainda não se diferenciaram. Elas podem gerar qualquer parte do corpo. Isso só será possível com o avanço de testes da ciência e da tecnologia, que é quem dá os elementos para a ciência evoluir" (DC, p. 58). Assim, vale refletir: "vocês estão vendo que quando aprendemos a história da ciência vemos que não é fácil ser cientista. Tem que provar tudo. Então, Yago, se quer ir para a medicina, para você ter sucesso, você precisa convencer a muita gente com sua teoria" (DC, p. 59). É com pesquisa que se justifica a necessidade de uma intervenção. É com testes que se avança em uma descoberta. É com convencimento que se obtém sucesso frente aos pares. É com embasamento empírico que se ganha autoridade.

Nesse processo de produção de verdades, seria necessário entender, ainda, que a ciência é cumulativa e coletiva, que nenhum saber novo pode ser autorizado se não considerar os pares. Por isso, nenhuma lição pode ser esquecida. Por estar ligada à enunciação de que a ciência é cumulativa, suas verdades são somadas uma às outras com o passar dos anos: "está vendo gente, a ciência não se faz sozinha. Cada um vai adicionando alguma ideia para sempre ir melhorando a teoria" (DC, p.47). Além de enunciações acerca da acumulação e coletividade, podem ser encontradas também no livro didático enunciações em torno do convencimento, da necessidade de se provar tendo a coletividade como testemunha, ao serem relatadas as impressões de Oersted, em 1820, sobre seus testes com eletricidade. Nesse caso, o cientista faz reflexões: "eu mesmo realizei experimentos relacionados ao tema proposto, mas os fenômenos que descobri, nessas ocasiões, repeti na presença desses homens tão sábios" (APEC, 2006, p. 206). Ele se deu conta de que não adiantava apenas realizar experimentos para se obter o status de autorizado. Era necessário que homens importantes vissemno realizando para que seus resultados tivessem credibilidade.

Ao se acionar o dispositivo da experimentação, deseja-se atingir "as coisas e os homens" (STENGERS, 2000, p. 104), apontando aqueles que não aceitam o desafio da prova em laboratório por meio da prática de desqualificação. Desqualificado é tudo que não é científico, que não foi experimentado pelo método, ou seja, é o senso comum, o mito, a lenda. Em atividade do livro, questiona-se "o que diferencia um mito de uma teoria científica" (APEC, 2006, p. 89). Uma aluna, por exemplo, responde ao ser solicitada: "mito é quando você faz uma pesquisa e desenvolve aquela ideia para ver se é ou não mito. Lenda é quando acredita e pronto". Ângela: "e o científico?". A aluna responde: "Ah, a é é verdade, não élenda". Ângela segue: "pois é gente, há investigação 
científica, uma pesquisa com hipóteses, observação, experimentação" (DC, p. 55). Nessas enunciações, vê-se como "práticas constitutivas de domínios de objetos e de conceitos no interior das quais as oposições do científico e do não-científico, da ilusão e da realidade, do verdadeiro e do falso, poderiam assumir seus efeitos" (FOUCAULT, 2010, p. 42).

Com a prática da desqualificaşão, produz-se uma posição de sujeito desqualificado cientificamente. Seriam os sujeitos não-científicos, que não explicam os acontecimentos por meio dos conhecimentos científicos, que possuem crenças religiosas ou crenças não testadas cientificamente, que são afeitos aos mitos e às lendas. São, ainda, sujeitos que não se baseiam em fatos ou em verdades comprovadas, são o outro da ciência. Ao longo das observações no currículo investigado, presenciamos docentes referirem-se a esse sujeito desqualificado. Esses sujeitos, para o currículo estudado, seriam mães, avós, irmãs que desconhecem os saberes científicos na cozinha; seriam as empregadas domésticas que descuidam da saúde das famílias; seriam os pais que não entendem o funcionamento dos dispositivos de segurança do automóvel; seriam os/as religiosos/as; seriam os povos do campo, da floresta que creem em lendas.

Em outra aula, ainda se abordava essa temática e Jonas diz: "a diferença é que o mito é baseado na fé, no sobrenatural. Já a ciência vem de muitos anos de estudo". Helen, em seguida, diz: "o mito é sobrenatural, é magia. O conhecimento científico não. Ele é baseado em fato". Ângela, então, adverte: "complicado é quando a ciência se mistura com a religião. Isso sim é complicado. Vamos para a próxima questão?” (DC, p. 57). Nesse embate entre ciência, senso comum, mito, sobrenatural, religião e lenda, quem deve prevalecer é a primeira: "o senso comum diz que eu estou fazendo força. A Física diz que não!" (DC, p.48). Nesse discurso, a ciência procede "pela desqualificação da 'não ciência' a que sucede" (STENGERS, 2000, p. 32). Verificase, aí, um conflito nesse discurso. Se o discurso pedagógico dos perfis conceituais, que também atravessa o currículo experimental, acredita na convivência entre saberes diferentes - explicações, visões diferenciadas a depender de cada contexto em que o saber é solicitado ao/à aluno/a -, com a prática de desqualificação, objetiva-se dizer que o perfil conceitual do sujeito da ciência é o único autorizado, é o perfil verdadeiro.

O que chamamos de desqualificação não é o ato de se autonomear como superior ou qualificado, mas sim o ato de não autorizar, de descartar outros saberes do conjunto de verdades por eles não serem produzidos pelas mesmas vias que o científico. Além disso, desqualificar não é dizer que os saberes não-científicos estão fora desse currículo. Desqualificar é fazer entender que "as explicações científicas diferem-se das místicas, das religiosas e daquelas que refletem 
nossas impressões e opiniões" e que esses saberes não-científicos logo devem ser substituídos pelos científicos. Afinal, como anunciado no livro didático, "a ciência nos obriga a manter a mente aberta a novas ideias, sem prejuízo do exame rigoroso dos desdobramentos que essas ideias podem gerar" (APEC, 2006, p. 86). Então, "você tem um conhecimento prévio, mas ele não pode ser taxativo" (DC, p.40). O sujeito investigativo tem de estar aberto às modificações e aceitar o conhecimento da ciência quando ela consegue provar a verdade. Foi desse modo que a ciência conseguiu 'inventar o dispositivo capaz de fazer calar os rivais, de instituir uma situação de comprovação cuja meta é o poder de representar" (STENGERS, 2000, p. 152).

Assim, qualificada é toda a verdade produzida utilizando-se de: evidências, fatos, testes, experimentação. E "o que é uma evidência, Odália?". Aline não deixa a aluna solicitada responder porque logo responde: "São fatos!". Então, Ângela segue: “é algo que eu posso constatar, é algo que meus órgãos do sentido podem evidenciar, como um calor que sentimos. Isso é uma evidência de que a temperatura aumentou" (DC, p. 57). Ao recolher outros trechos que se referem à ciência, encontro frases de discentes, tais como: "evidências concretas"; "é algo que está aberto à mudança", "é a verdade", "o que não pode ser contestado, pois passou pelas experiências do cientista". A prática científica seria aquela que se baseia em evidências e fatos. O fato seria "algo indiscutível, que ninguém, pelo menos até agora, o coloca em questão" (FOUREZ, 1995, p. 42) de um modo tal que "conquistaria sua autonomia" (LATOUR, 2002, p. 39). A evidência seria "a melhor prova e demonstração que não existe necessidade de qualquer coisa como um regime de verdade acrescentando-se de qualquer modo ao próprio verdadeiro" (FOUCAULT, 2010, p.70).

Observa-se que a ciência produzida no currículo experimental analisado é uma ciência como sinônimo de verdade. É uma ciência cujo método principal de investigação é o experimento. É uma ciência que tem efeitos de autoridade, de sobreposição a outros saberes da vida cotidiana. A ciência produzida nesse laboratório escolar se aproxima fortemente da ciência criticada por Foucault, no sentido de suas práticas e verdades condicionarem os sujeitos a conjunto de comportamentos tidos como mais autorizados do que os de outros saberes. É a ciência analisada amplamente por Stengers e Latour em seus estudos, quando analisaram laboratórios científicos e encontraram modos de comportamentos próprios aos fazedores de verdades científicas.

Se a ciência é produzida como verdade, rigor, evidência, fato, alunos / as e professores/as são solicitados/as a realizar prática de crítica. Sabendo-se disso, alunos/as são requeridos / as a avaliar, a ser críticos / 
as, a escrever narrativas científicas sobre o que vivenciam. Após uma atividade prática, a professora divide os/as alunos/as em grupos e pede uma análise crítica dos textos (DC, p. 55). No final de outra aula, pede-se um texto crítico: "Vocês não vão me resumir texto. Vocês vão conversar com o texto e criticar" (DC, p. 57). Ao final do roteiro sobre densidade dos refrigerantes, pede-se que façam "um relato do que foi observado e uma explicação para desvendar o mistério", como uma conclusão. Ao realizarem uma escrita cientificamente crítica - isto é, a partir do regime de saberes científicos, solicita-se que reorganizem os seus saberes e vejam os resultados da experimentação sob essas verdades -, almeja-se o governo das condutas, das formas de visualizar o mundo. Tal regime de saberes "é o ponto em que se articula um regime político de obrigação e de constrangimento particular que é o regime de verdade" (FOUCAULT, 2010, p. 77).

Não se trata apenas de seguir roteiros e protocolos ou de cumprir determinadas práticas. Para serem, de fato, autorizados, tem-se de refletir sobre tais procedimentos pela técnica de reflexão. Quando, no livro didático, comenta-se sobre o experimento que vem para contestar formulações de Lamarck, alunos/as são chamados/as a refletir por que os procedimentos desse experimento são contestados pelos neolamarckistas (APEC, 2006, p. 90). Em outro livro, há experimentos que dão "evidências" sobre o papel do oxigênio e da luz para os seres vivos, porém, com "conclusões errôneas" feitas por cientistas do século XVII. Aí, alunos/as são solicitados/as a formular conclusões corretas a partir do que foi apresentado como procedimento de experimentação (APEC, 2009, p. 153). Há, ainda no currículo investigado, processos mais diretos de avaliação do método usado na aula prática de extração do DNA de morangos: "qual a função dos reagentes?" ou "por que trituramos o morango no início?".

É necessário, ainda, refletir acerca de condutas e acontecimentos por meio de um procedimento experimental. $\mathrm{Na}$ atividade sobre densidade dos refrigerantes, pergunta-se: "você é capaz, de descobrir qual refrigerante está representado [em imagem de rótulos diet ou normal]?". Em outra situação, questiona-se: "ao observar o volume final da mistura [há uma foto do experimento], o que você pode constatar?" (APEC, 2006, p. 32). Em outra atividade do livro, ditase os procedimentos de um experimento envolvendo eletricidade e questiona-se "o que deve acontecer?" (APEC, 2006, p. 51). Depois de relatar um experimento sobre o "ovo voador", solicita-se a interpretação dos resultados e suas aplicações no dia a dia como, por exemplo, as redes usadas por bombeiros para amenizar impactos (APEC, 2006, p. 160). Ao percorrerem o currículo estudado e testarem 
saberes científicos, alunos/as passam a ser capazes no laboratório. Afinal, "essa transformação de alguém que não sabe em alguém que sabe é o problema [...] da educação" (FOUCAULT, 2010, p.54). Por isso, os currículos de ciências têm-se ocupado a disponibilizar o ensino investigativo e, assim, instrumentalizar os sujeitos da experimentação.

Ao avaliarem e refletirem sobre práticas da experimentação, docentes e discentes são chamados/as a um exercício de si, de avaliação de seus procedimentos e comportamentos sob parâmetros de cientificidade. Esses mecanismos de avaliação e reflexão são utilizados como "um fator que [favorece] a engrenagem dos dispositivos normalizadores e das técnicas de fabricação de indivíduos" (SANTIAGO, 2008, p. 54). A experimentação não apenas produz conhecimento científico; ela dá passagem e remete ao comportamento humano, à forma de olhar e relacionar-se com o mundo e, consequentemente, consigo mesmo. Se tudo isso - procedimentos e comportamentos dos/as operadores/ as - for devidamente garantido, eis que muitas outras condutas serão produzidas e demandadas pelo discurso do ensino por experimentação.

Se o dispositivo da experimentação é operacionalizado na ciência para conferir e consolidar o método científico moderno, derrubar teorias, promover alguns em detrimento de outros, produzir saberes e validar verdades (STENGERS, 2000; LATOUR, 2000), no currículo investigado, ele aciona um sujeito investigativo quando se deseja alcançar o aprendizado dos saberes e procedimentos científicos. As práticas do discurso do ensino por experimentação - revelação, registro, teste, teorização, autorização, desqualificação e crítica - são demandadas para: modificar conhecimentos prévios e cientifizar o que era senso comum; provar qual conhecimento é verdadeiro em situações de dúvida; ensinar procedimentos investigativos, rígidos e eficientes ao se desvendar a natureza; desqualificar a não-ciência; usar racional e convenientemente instrumentos, objetos e roteiros; criticar o saber não-científico; convidar sujeitos a agir de modo científico sobre si mesmos e o mundo. O sujeito investigativo é aquele que sairá do currículo experimental, exigirá relatos e saberes mais sérios, agirá de modo diferente do que agia porque terá uma ação científica.

\section{SUJEITOS HOMO EXPERIMENTALIS}

Se esperam com ansiedade as aulas, participam das atividades, se empenham em argumentar com termos científicos, seguem passos do roteiro, querem que seus grupos consigam realizar práticas, almejam lógica nos resultados dos experimentos, ensinam uns/umas aos/às outros/as com ou sem professor/a, aplicam os saberes construídos 
em aula no cotidiano, é porque o currículo experimental distribui alguma magia sobre os/as estudantes. Se tais alunos/as posicionam-se como Homo experimentalis, é porque o currículo estudado produz um desejo pela empiria ao fabricá-la como prática que revela a verdade, confere prestígio, garante certeza, oferta utilidades.

Em uma prática do currículo analisado, pergunta-se se a planta carnívora "oferece perigo ao homem?" e a resposta de um aluno foi: "não, eu já testei em uma planta que tem lá em casa e não aconteceu nada" (DC, p. 61). Em outro momento, pergunta-se por que a taxa de fotossíntese cai no calor. Faz-se essa pergunta várias vezes na tentativa de que alunos/as respondam. Depois de um tempo, um aluno diz: "você está querendo que a gente levante hipóteses, é isso?" (DC, p. 63). Com o discurso do ensino por experimentação, em que professores/as e alunos/as procedem para manifestação da verdade, "o sujeito pode ser o agente ativo graças ao qual a verdade emerge” (FOUCAULT, 2010, p.65). É nesse processo que os sujeitos identificam-se com a ciência, posicionamse nesse discurso e passam a agir de acordo com suas verdades.

Sujeitos investigativos da experimentação, ou sujeitos Homo experimentalis, no entanto, não são exclusividades de laboratórios científicos ou de currículos escolares, como foi detalhado aqui. Assim, trata-se de um acontecimento mais amplo, de mudança de racionalidade desde a construção da ciência moderna e, mais especificamente, com a ciência contemporânea. É possível encontrar, facilmente, situações cotidianas em que nos posicionamos como tais. Seria possível, hoje, por exemplo, escolhermos um cosmético que não é testado dermatologicamente em detrimento de outro testado com indicativos em sua embalagem? E um brinquedo para nossos/ as filhos/as sem a certificação de segurança ou indicativo de idade/ peso? Por isso, propagandas são pensadas para "agradar" tais sujeitos: pensar em uma fórmula perfeita para todos os tipos de cabelo ${ }^{14}$; testar dermatologicamente e prometer limpeza profunda contra espinhas ${ }^{15}$; comparar marcas via testes ${ }^{16}$; avaliar produtos em diferentes manchas, tecidos, cores e temperaturas ${ }^{17}$ ou quanto à absorção ${ }^{18}$; medir a eficácia dermatológica de novas fórmulas ${ }^{19}$; unir a diversidade brasileira, pesquisa e sustentabilidade ${ }^{20}$; examinar com detalhe a gengiva ${ }^{21}$.

Nos últimos anos, o Ministério da Ciência, Tecnologia e Inovação e o Ministério da Educação têm investido na popularização da ciência por meio do ensino. Em parceria, diversas agências de fomento estaduais e federais têm incentivado a participação de escolas e universidades em tal popularização $0^{22}$ por se acreditar na necessidade de: "promover feiras de ciências e exposições", "divulgar as invenções da ciência e tecnologia", "estimular a carreira técnico-científica", "em especial, na população mais 
jovem". Outra ação, desenvolvida durante a Rio+20, foi a reunião e exposição dos projetos de popularização da ciência com temática ambiental desenvolvidos no país, tendo a participação nacional e internacional ${ }^{23}$.

Vê-se, portanto, como o dispositivo da experimentação não restringe o seu alcance aos laboratórios científicos. Esse dispositivo invade a escola, os noticiários, os filmes, a televisão, os produtos de higiene pessoal, de estética e de limpeza doméstica, os rótulos de alimentos e de remédios, as embalagens de brinquedos. Todos esses investimentos em mostrar a ciência contemporânea na vida e levar os fazeres científicos para o público têm sido apontados como estratégicos: ora como vitrine, em que o conhecimento científico é imposto como verdade ao público em geral (FOUREZ, 1995; STENGERS, 1990); ora como forma de empoderamento da população. Aqui, interessou-nos pensar em que sujeitos se deseja produzir quando a ciência toma para si a vida, o mundo e os seres. Ao se lançar mão dessa estratégia, em editais, jornais ou programas televisivos, pode-se encontrar muitas demandas aos sujeitos Homo experimentalis: "cidadão autônomo", "indivíduos com discernimento", "sujeitos que dominam os saberes científicos", "pessoas capazes de viver no mundo atual", "cidadãos com argumentos para debaterem questões polêmicas", "pessoas preparadas para a vida". A produção desses sujeitos extrapola, portanto, o currículo aqui analisado e pode ser encontrada em tantos outros espaços e situações.

\section{REFERÊNCIAS}

APEC. Ação e Pesquisa em Educação em Ciências. Construindo Consciências: $9^{\circ}$ ano. São Paulo: Ed. Scipione, 2006.

APEC. Ação e Pesquisa em Educação em Ciências. Construindo Consciências: $7^{\circ}$ ano. São Paulo: Ed. Scipione, 2009.

BRASIL. Guia de Liuros Didáticos: PNLD 20011 - Ciências. Brasília: Ministério da Educação, Secretaria da Educação Básica, 2010.

CARDOSO, L. de R. Nos rastros de uma bruxa, compondo metodologias alquimistas. In: MEYER, D. E.; PARAÍSO, M. A. (Org.). Metodologias de pesquisas pós-críticas em Educação. Belo Horizonte: Mazza, 2012. p. 219-241.

CLIFFORD, J. Introduction: partial truths. In: CLIFFORD, J.; MARCUS, G. E. Writing culture: the poetics and politics of ethnography. Berkeley: University of California Press, 1986. p. 1-26. FOUCAULT, M. História da sexualidade II: o uso dos prazeres. São Paulo: Graal, 2006.

FOUCAULT, M. A arqueologia do saber. $7^{\mathrm{a}}$ ed. Rio de Janeiro: Forense Universitária, 2005.

FOUCAULT, M. As técnicas de si. 1982. p. 01-23, Disponível em < http://vsites.unb.br/fe/ tef/filoesco/foucault/tecnicas.pdf>. Acesso em: Abril de 2012.

FOUCAULT, M. Sobre a justiça popular. In: M., Roberto (org.). Microfísica do poder. $24^{\mathrm{a}}$ ed. Rio de Janeiro: Edições Graal, 2007a. p. 39-68. 
FOUCAULT, M. Sobre a história da sexualidade. In: MACHADO, R. (org.). Microfísica do poder. $24^{a}$ ed. Rio de Janeiro: Edições Graal, 2007b. p. 243-276.

FOUCAULT, M. Do governo dos vivos: curso no Collège de France, 1979-1980 (excertos). São Paulo: Centro de Cultura Social; Rio de Janeiro: Achiamé, 2010.

FOUREZ, G. A construção das ciências: introdução à filosofia e ética das ciências. São Paulo: Editora da UNESP, 1995.

GIOPPO, C.; SCHEFFER, E. W. O.; NEVES, M. C. D. O ensino experimental na escola fundamental: uma reflexão de caso no Paraná. Educar, Florianópolis, Editora da UFPR, n. 14, p. 39-57, 1998.

JORDÃO, P. A antropologia pós-moderna: uma nova concepção da etnografia e seus sujeitos. Revista de Iniciação Científica. v. 4, n.1, p. 35-51, 2004.

LATOUR, B.; WOOLGAR, S. A vida de laboratório: a produção dos fatos científicos. Rio de Janeiro: Relume Dumará, 1997.

LATOUR, B. Jamais fomos modernos: ensaio de antropologia simétrica. $2^{a}$ reimpressão. Rio de Janeiro: Ed. 34, 2000.

LATOUR, B. Reflexão sobre o culto moderno dos deuses fe(i)tiches. Bauru, SP: EDUSC, 2002.

MAKNAMARA, M. Currículo, gênero e nordestinidade: o que ensina o forró eletrônico? 2011. 152 f. Tese de Doutorado (Educação) - Faculdade de Educação, UFMG, Belo Horizonte, 2011.

MARCELLO, F. de A. Sobre os modos de produzir sujeitos e práticas na cultura: o conceito de dispositivo em questão. Currículo sem Fronteiras, Belo Horizonte, v. 9, n. 2, p. 226-241, jul./dez. 2009.

PARAÍSO, M. A. Política da subjetividade docente no currículo da mídia educativa brasileira. Educação e Sociedade, Campinas, v. 27, n. 94, p. 91-115, 2006.

PARAÍSO, M. A. Currículo e mídia educativa brasileira: poder, saber e subjetivação. Chapecó: Argos, 2007.

PORTER, Roy. Das tripas coração: uma breve história da medicina. Rio de janeiro: ed. Record, 2004.

SANTIAGO, J. Foucault e o neo-higienismo contemporâneo. In: PASSOS, I. C. F. Poder, normalização e violência: incursões foucaultianas para a atualidade. Belo Horizonte: Autêntica Editora, 2008. p. 53-62.

SILVA, T. T. da. Documentos de identidade: uma introdução às teorias de currículo. 2ed. Belo Horizonte: Autêntica, 2003.

STENGERS, I. Quem tem medo da ciência?: ciências e poderes. São Paulo: Siciliano, 1990.

STENGERS, I. As políticas da razão: dimensão social e autonomia da ciência. Coleção o saber da Filosofia. Lisboa: Edições 70, 2000.

VALADARES, J. O Ensino Experimental das Ciências: do conceito à prática: Investigação/ Acção/Reflexão. Proformar, Rio de Janeiro, v. 13, p. 1-15, 2006.

\section{NOTAS}

${ }^{1}$ Nas edições da Veja: A força do Laser (n. 2146), Segredos da memória (n. 2147), Nova ciência da pele (n. 2154), DNA (n. 2168), A nova medicina do coração da mulher (n. 2215), Longevidade (n. 2221).

${ }^{2}$ Em pesquisa na Folha de São Paulo, encontramos 2293 reportagens relacionadas. Disponível em $<$ searc h.folha.com.br/search?q=experi $\%$ EAncia $\% 20$ ciencia\&site=jornal $>$, com acesso em 18 Setembro de 2012. 
${ }^{3}$ Alguns filmes: Homem-Aranha, <http://spiderman.sonypictures.com>; O dia depois de amanhã, <http://www.thedayaftertomorrow.com>; Avatar, disponível em $<$ http://www. avatarmovie.com/>.

${ }^{4}$ Texto disponível no site < http://www.discoverykidsbrasil.com/personagens/sid/ educacional/>, na seção destinada aos pais, onde explicações são dadas em torno do que crianças podem aprender com o desenho.

${ }^{5}$ Tais como: "Professores de Ciências", <http://www.orkut.com.br/Main\#Community? cmm=5772166>; "Sou professor(a) de Ciências", <http://www.orkut.com.br/Main\# Community?cmm=8578572>; "O Ensino de Ciências". <http://www.orkut.com.br/ Main\#Community? $\mathrm{cmm}=1664574>$. Todos esses sites foram acessados em $1^{\circ}$ de fevereiro de 2012.

${ }^{6}$ Tais como: "Odeio Ciências", <http://www.orkut.com.br/Main\#Community?cmm =1944752>; "Eu odeio aula de experimental", <http://www.orkut.com.br/ Main\#Community?cmm=1944752>. Ambos foram acessados em 1º de Fevereiro de 2012.

7 "Energia Cinética", <http://www.youtube.com/watch?v=6aFcF--NouA>; "Garrafa que fuma", <http://www.youtube.com/watch?v=qwviBlVa2Ek\&feature=related $>$; "O ar ocupa espaço", <http://www.youtube. com/watch?v=uPRr1 ryb92M>. Todos os referidos vídeos foram acessados em 04 de Fevereiro de 2012.

${ }^{8}$ Tais como: "Mico Lelis: buscador para professores de ciências", <http://www.facebook. com/apps /application.php?id=246140332067558>; "Projeto para Ensino Básico Laboratório Móvel de Ensino de Ciências", <http://www.facebook.com/groups/ ProjetoLMEC/>; "Sujeito Experimental-Psicofísica", <http://www.facebook.com/group. php?gid $=109922744005>$. Sites acessados em 18 de setembro de 2012 .

${ }^{9}$ Em 2003, o Ministério da Ciência e Tecnologia, apoiado pela UNESCO, anunciou implantar um laboratório para o ensino de ciências em todas as escolas públicas brasileiras até o fim do mandato do governo Lula <http://www.paranaonline.com.br/editoria/especiais/news/ $38201 /$ ? noticia $=$ governo + quer + laboratorio + de + ciencias + em + todas + as + escolas + publicas $>$. Centros de pesquisa em ensino elaboram projetos para que a experimentação chegue a todos: "Experimentação" da UFPA < http://www2.ufpa.br/ppgf experimentacao/ projeto.html> e "Usina Ciência" da UFAL < www.ufal.edu.br/ufal/extensao/usinaciencia>. Em outros países, isso também é observado. Criado em 2007 nos EUA, BIOBUS fornece ajuda no ensino de ciências para mais de 10 mil estudantes carentes por ano em NY $<$ http://www2.uol. com.br/sciam/noticias/biobus_o_laboratorio_andante_de_ciencias_ para_escolas_carentes.html>

${ }^{10}$ Notícia acessada em 10 de junho de 2010 e disponível no portal do MEC através do site $<$ http://portal.mec.gov.br/index.php?option=com_content\&view $=$ article\&id=13401:estu dantes-de-quimica-usam-sucata-para-criar-produtos\&catid=209>.

${ }^{11}$ Notíciaacessadaem12 dejunhode2010edisponível noportal doMECatravés do site <http:// portal.mec.gov.br $/$ index.php?option=com_content\&view $=$ article\&id $=8199 \&$ catid $=211>$.

${ }^{12}$ Notícia acessada em 17 de abril e disponível em <http://sergyovitro.blogspot. com/2011/01/parceria-tenta-melhorar-aulas-de.html>.

${ }^{13}$ Nas análises que seguem, fragmentos de tal Diário são trazidos e identificados pela sigla DC.

${ }^{14}$ Propaganda do Shampoo Seda disponível em: <http://www.youtube.com/ watch? $\mathrm{v}=\mathrm{VS} 332 \mathrm{SIEhtE}>$, com acesso em 06 abr. 2012.

${ }^{15}$ Propaganda do Sabonete Protex disponível em: <http://www. youtube.com/ watch?v=_1Y_uCfwfJw >, com acesso em 06 abr. 2012. 
${ }^{16}$ Propaganda do Inseticida Raid disponível em: <http://www.youtube.com/ watch? $\mathrm{v}=\mathrm{b} 6 \mathrm{mLc} 9 \mathrm{~K} 0 \mathrm{X} 98 \&$ feature $=$ endscreen $\& \mathrm{NR}=1>$, com acesso em 06 abr. 2012.

${ }^{17}$ Propaganda do Vanish O2 disponível em: <http://www.youtube.com/watch?v=DZ I73B3XWkw>, com acesso em 06 abr. 2012.

${ }^{18}$ Propaganda do Sempre Livre disponível em: <http://www.youtube.com/watch?feature= endscreen $\& N R=1 \& v=05 z M o L k y X$ A0>, com acesso em 06 abr. 2012.

${ }^{19}$ PropagandadoRepelexdisponívelem:<http://www.youtube.com/watch?v=ZRi7hfi5Moo>, com acesso em 06 abr. 2012.

${ }^{20}$ Propaganda do Gasolina Petrobras disponível em: < http://www.youtube.com/watch?v=jGE MJ1UHqxo>, com acesso em 06 abr. 2012.

${ }^{21}$ Propaganda do OralB disponível em: <http://www.youtube.com/user/ oralbbrasil?v=7Ltl5qNfJCI $>$. Acesso em 06 abr. 2012.

${ }^{22}$ Editais de tais agências podem ser consultados: FAPESB < http://www.iat.educacao. ba.gov.br/node/3072>, FAPESE < http://www.fapitec.se.gov.br/modules/tinyd0/ index.php?id=108>, FAPEMA < http://www.jornal pequeno.com.br/2011/9/9/editalpara-popularizacao-da-ciencia-inscreve-ate-segunda-169269.htm>, MIC < http://www. fai.ufscar.br:8080/FAI/noticias/inscricoes-para-editais-de-popularizacao-da-cienciaterminam-no-dia-5>, FAPEMIG < http://www.anpei.org.br/imprensa/noticias/fapemigdivulga-resultado-do-edital-de-popularizacao-da-ciencia/>, FAPERJ <http://www. faperj.br/interna.phtml?obj_id=6998>, FAPEAM < http://www.sect.am.gov.br/noticia. php?cod=6067> . Todos com acesso em 07 de junho de 2012.

${ }^{23}$ Tal evento é denominado de Armazém 4. Maiores informações podem ser encontradas em $<$ http://www.mct.gov.br/index.php/content/view/339480.html>.

Recebido: 23/07/2013

Aprovado: 21/04/2015

Contato:

Universidade Federal de Sergipe

Campus Prof. Alberto Carvalho

Departamento de Educação.

Av. Ver. Olimpio Grande

Itabaiana |SE | Brasil

CEP 49.500-000 